\title{
Maximal acid response of Pavlov pouches to food and histamine
}

\author{
A. MARVIN BROOKS AND MORTON I. GROSSMAN \\ From the Veterans Administration Center and UCLA School of Medicine, Departments of Medicine \\ and Physiology, Los Angeles, California, USA
}

SUMMARY Secretion of gastric acid in response to histamine, insulin, and a meal of liver, with and without $5 \%$ bone dust, was studied in three dogs with Pavlov pouches and gastric fistulas. The ratios of insulin-induced to histamine-induced secretion were the same in pouch and main stomach indicating that their innervation was equivalent. Meals of a liver and bone dust mixture in amounts of 11 to $44 \mathrm{~g} / \mathrm{kg}$ resulted in Pavlov pouch acid outputs that were 34 to $56 \%$ higher than the maximal response to histamine $(\mathrm{P}<0.05$ to $<0.001)$. Liver without bone dust also produced higher acid outputs than histamine. These results indicate that combinations of endogenously generated stimuli can produce a potentiated gastric response which exceeds that produced by histamine alone.

In dogs with vagally denervated pouches histamine and food in maximal doses produced about the same rate of acid secretion (Thomas and Forrest, 1967). Indirect studies in man using changes in blood base gave similar results although the author recognized that his technique might underestimate food-induced gastric secretion (Rune, 1966). The present investigation compares the gastric acid response to food and histamine in dogs with innervated (Pavlov) pouches.

\section{Methods}

Three dogs weighing $12 \cdot 7$ to $16.2 \mathrm{~kg}$ were prepared with a Gregory cannula (Gregory, 1958) in a Pavlov pouch (Emås, Swan, and Jacobson, 1967) and a Thomas cannula (Thomas, 1941) in the main stomach. Tests were started two weeks after surgery and were done at intervals of at least 48 hours.

After a fast of 18 hours or more, 15-min collections of gastric juice were obtained from the gastric fistula and Pavlov pouch. In feeding experiments the gastric fistula was closed throughout. Volumes were measured and $0.2 \mathrm{ml}$ samples were titrated to $p \mathbf{H ~} 7$ on an automatic titrator. ${ }^{1}$

An intravenous infusion of $154 \mathrm{mM} \mathrm{NaCl}$ was delivered at $60 \mathrm{ml}$ per hour by a peristaltic pump ${ }^{2}$ throughout each study. Histamine was added to the $\mathrm{NaCl}$ infusion and insulin was rapidly injected through a three-way stopcock in the tubing of the intravenous infusion.

Four basal 15-min collections were obtained and the gastric stimulant (food, histamine, or insulin) were given. A further 16 15-min collec- 


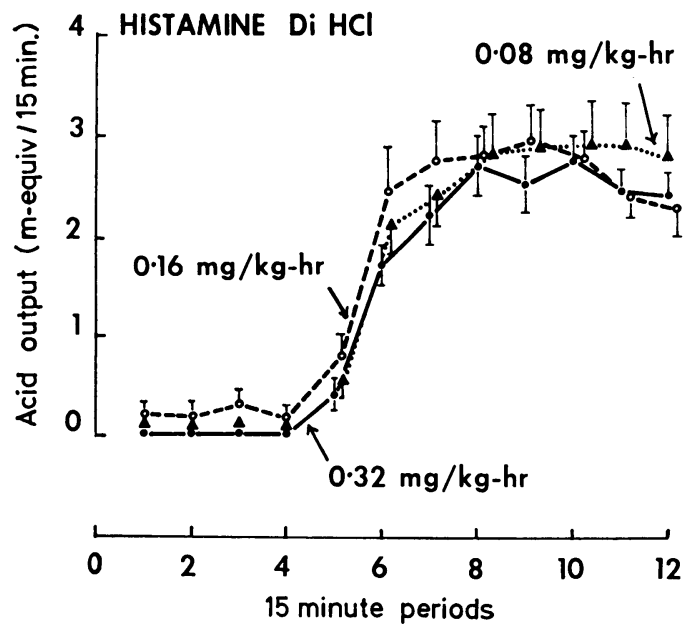

Fig. 1 Mean 15 min-Pavlov pouch acid outputs in response to histamine infusion. Each point is the mean of two observations on each of three dogs. The vertical lines are the standard errors of the mean.

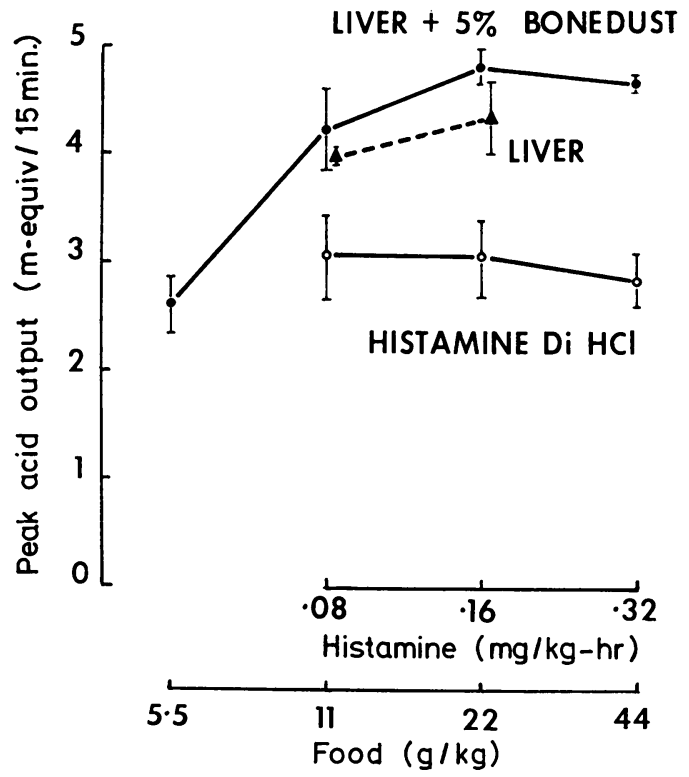

Fig. 2 Mean peak 15-min Pavlov pouch acid outputs in response to histamine, liver-bone dust mixture, and liver alone. In histamine and liver-bone dust studies each point represents two observations on each of three dogs. In experiments using liver without bone dust each point is the mean of one observation on each of three dogs.

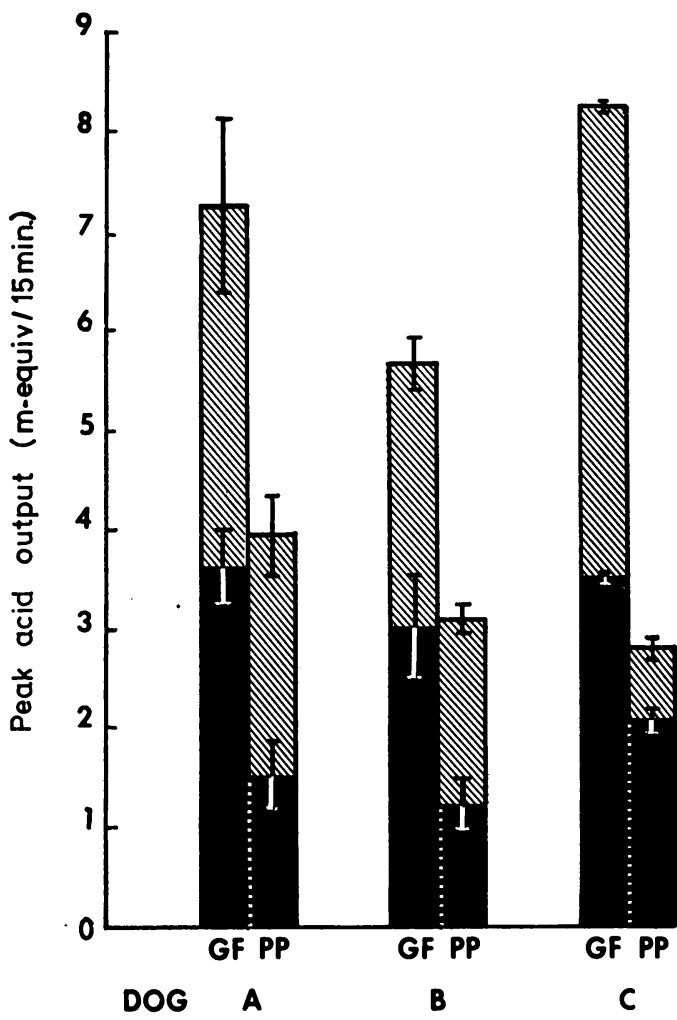

Fig. 3 Comparison in each dog of mean peak 15-min acid output from Pavlov pouch and gastric fistula in response to insulin (black) 1.0 units $/ \mathrm{kg}$ and to histamine (shaded).

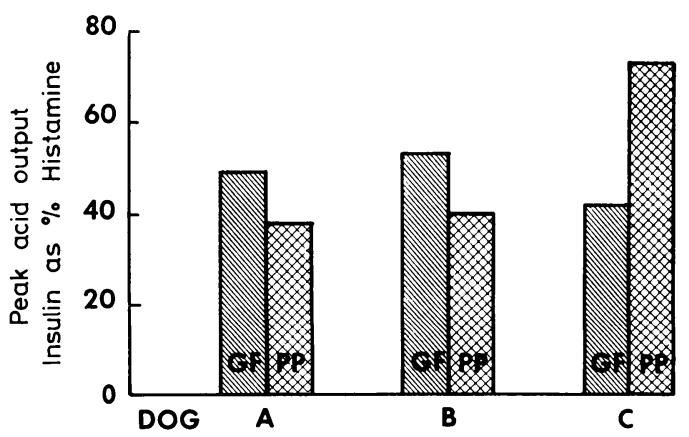

Fig. 4 Mean peak 15-min insulin-stimulated acia output from Pavlov pouch and gastric fistula expressed as a percentage of histamine response (derived from data of Figure 3). 

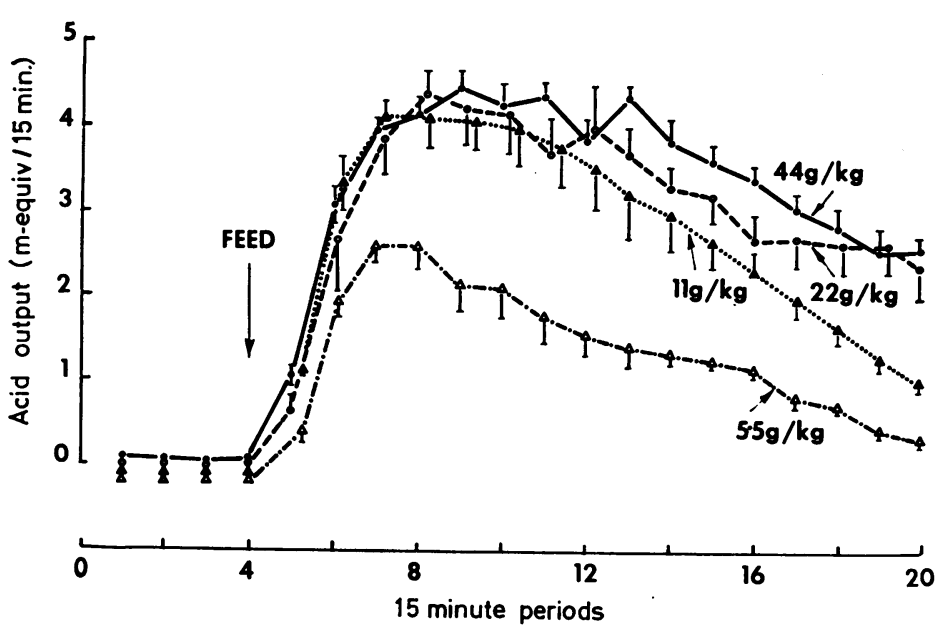

Fig. 5 Mean 15-min Pavlov pouch acid outputs in response to various size meals of meat and bone dust mixture. Each point is the mean of two observations on each of three dogs.
Results

Histamine produced a sustained acid output from the Pavlov pouch which was approximately equal for the three doses used (Fig. 1). There was no significant difference between the three doses in the peak 15-min acid output (Fig. 2). The responses of the gastric fistula and the Pavlov pouch to histamine and insulin are shown in Figure 3. To compare the response to insulin of the gastric fistula and Pavlov pouch each is expressed as a percentage of its histamine response (and presumably as a percentage of its parietal cell mass) so that absolute differences in the secretory rate of gastric fistula and Pavlov pouch are eliminated (Fig. 4). Insulin-stimulated acid output was $48.2 \pm 3.2 \%$ of the histamine response from the gastric fistula and $49.7 \pm$ $11.5 \%$ of the histamine response from the Pavlov pouch. This suggests that the pouch and main stomach do not differ significantly in the degree of vagal innervation.

The three highest doses of liver-bone dust mixture produced peak acid outputs that were 33.7 to $56.2 \%$ greater than the peak histamine response (Fig. 2, P $<0.05$ to $<0.001$ ). The acid output induced by smaller meals was less sustained than with larger meals (Fig. 5). Liver without bone dust produced peak acid outputs that were 29.5 to $41.4 \%$ higher than the peak histamine output $(\mathrm{P}<0.10$ to $<0.05)$.

tions were obtained after food and eight after histamine or insulin. Only one dose of a stimulant was given in any day and the order of administration was randomized. Two observations per dog were made for each dose of stimulant except as noted.

Histamine dihydrochloride was administered in doses of $0.08,0 \cdot 16$, and $0.32 \mathrm{mg} / \mathrm{kg} \mathrm{hr}$. Regular insulin ${ }^{1}$ was given as a rapid intravenous injection in a dose of 1 unit $/ \mathrm{kg}$.

The meal consisted of beef liver which had been cooked, ground, and frozen. Small portions were thawed 12 hours before use and $5 \%$ bone dust was added. This mixture was given in meals of $5.5,11,22$, and $44 \mathrm{~g} / \mathrm{kg}$. Five hundred $\mathrm{ml}$ water was also offered at the time of the meal and usually completely consumed. Liver without bonemeal in doses of 11 and $22 \mathrm{~g} / \mathrm{kg}$ was given in one test in each dog.

Results are expressed as mean plus or minus standard error of the mean. The peak 15-min acid output was calculated by taking the mean of the highest two consecutive 15-min outputs. Analysis of variance was used in the statistical analysis (Snedecor and Cochran, 1968).

\section{Discussion}

We have been unable to find previous reports of the maximal secretory response to food in vagally innervated pouches. Code and Watkinson (1955) found that a standard meal of horse meat given as a single feed of $170 \mathrm{~g}$ or repeated feed of $15 \mathrm{~g}$ every 15 to 30 minutes produced about the same level of acid output as was achieved with maximal histamine infusion in Pavlov pouch dogs.

In a systematic study of dogs with vagally denervated (Heidenhain) pouches, Thomas and Forrest (1967) showed that the maximal acid output to a meal of meat and bone dust was about equal to the maximum elicited by histamine. Bone dust was added to meat because this mixture produced higher levels of gastric secretion than meat alone in dogs with denervated pouches (Öbrink, 1954). Large meals were required to duplicate the maximal response to histamine, approximately $80 \mathrm{~g} / \mathrm{kg}$ as a single feeding or 5 to $10 \mathrm{~g} / \mathrm{kg}$ every 15 minutes. Pentagastrin, a gastrin analogue, produced lower rates of secretion than histamine or food.

Our dogs with innervated pouches were fed a meal of liver and $5 \%$ bone dust similar to that given in the experiments of Thomas and Forrest (1967). These pouches, in response to considerably smaller meals (as low as $11 \mathrm{~g} / \mathrm{kg}$ ), 
secreted at a rate significantly greater than the maximal rate induced by histamine. These high Pavlov pouch responses are not peculiar to the meal employed in this study. A commercial dog food, Prime, produced rates of secretion from Pavlov pouches that were comparable to those induced by the liver-bone dust mixture (unpublished studies).

Not all agents which act by initiating both endogenous vagal and gastrin stimulation produce higher maximal responses than exogenous gastrin or histamine alone. For example, in the present study and other studies with insulin, which presumably involves vagal plus gastrin stimuli, the responses did not exceed the maximal histamine response. Similarly, Preshaw and Webster (1967) found that the maximal response to sham feeding (presumably involving both vagal and gastrin stimulation) was equal to, but did not exceed, the maximal response to histamine. We cannot specify exactly what conditions are required for combinations of endogenous stimuli to exceed the maximal response to histamine. Perhaps unidentified factors other than vagal stimulation and gastrin release are involved. For example, an intestinal gastrin that differs from antral gastrin may be involved in the response to feeding.

One might anticipate that the passage of acidchyme into the duodenum during feeding experiments would release inhibitors that could limit gastric secretion. In our experiments with feeding, duodenal acidification was probably present because in unpublished studies in dogs the $p \mathrm{H}$ in situ in the lumen of the proximal duodenum was found to vary between $p \mathrm{H} 2.9$ and 3.8 after a meat meal. Perhaps responses to meals might have been even higher if duodenal acidification were prevented.

Using gastric fistula dogs in which all the acid was diverted from the duodenum, Johnson and Grossman (1969) found that a combination of histamine and gastrin produced secretory rates about $70 \%$ greater than the maximal response to histamine alone. Responses higher than the maximal response to exogenous histamine have also been demonstrated in the presence of duodenal acidification. Gillespie and Grossman (1964) showed potentiation between bethanecol and histamine or gastrin, and Passaro, Gillespie, and Grossman (1963) showed potentiation between gastrin and histamine in Heidenhain pouch dogs. Andersson and Grossman (1965) showed potentiation between bethanechol and histamine in Pavlov pouch dogs. In all of these studies acid from the main stomach was entering the duodenum and it must be assumed that potentiation occurred despite duodenal acidification. Our histamine studies were conducted with acid diverted to the exterior through the open gastric fistula to prevent the possible release of inhibitors of histamine stimulated secretion (Code and Watkinson, 1955).
It is difficult to quantitate the gastric secretory response to feeding in man. Aspiration of the

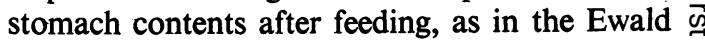
test meal, is limited by solid food, alkaline duodenal reflux, buffering of acid by the food, and gastric emptying. Rune (1966) has attempted to estimate gastric acid secretion indirectly by measuring the elevation in blood base which of accompanies the discharge of $\mathrm{H}^{+}$ions into the $\vec{\circ}$ gastric lumen. He found equal elevations in blood base in man during a meal and during histamine stimulation with simultaneous gastric aspiration. As he noted, food may have produced a greater output of acid than histamine since pancreatic secretion of bicarbonate during a meal would suppress the blood base elevation and lead to an underestimation of the acid secretory response to food.

There is controversy about the occurrence of potentiation of gastric acid secretion in various species. Johnson and Grossman (1969) have conclusively demonstrated in the dog that combinations of histamine and gastrin clearly exceed the highest rate of gastric acid secretion that can be achieved with either stimulant alone. Konturek and Oleksy (1967) found slight potentiation between histamine and pentagastrin in man. Checketts, Gillespie, and Kay (1968) showed that in 32 of 67 subjects insulin appeared to potentiate histamine. In a single subject studied by Makhlouf, McManus, and Knill (1968) gastrin combined with histamine or mechothane produced the same calculated maximum as gastrin alone. This study has demonstrated that combinations of hormonaland neural stimuli, endogenously initiated by food, are capable of producing a higher rate of gastric secretion in dogs than can be achieved by a single exogenous stimulant (histamine) alone.

The technical assistance of Raymond L. Melendez is gratefully acknowledged.

This study was supported by Veterans Administration research funds and by grant AM 8354 from the United States Public Health Service.

References

Andersson, S., and Grossman, M. I. (1965). Effect of vagal denervation of pouches on gastric secretion in dogs with intact or resected antrums. Gastroenterology, 48, 449-462.

Checketts, R. G., Gillespie, I. E., and Koy, A. W. (1968). Insulin potentation of the augmented histamine response. Gut, 9, 683-687.

Code, C. F., and Watkinson, G. (1955). Importance of vagal innervation in the regulatory effect of acid in the duodenum on gastric secretion of acid. J. Physiol. (Lond.), 130 , 233-252.

Emås, S., Swan, K. G., and Jacobson, E. D. (1967). Methods of studying gastric secretion. In Handbook of Physiology, p. 747. Sect. 6, Vol. II, edited by C. F. Code. Waverly Press, Baltimore.

Gillespie, I. E., and Grossman, M. I. (1964). Potentiation between urecholine and gastrin extract and between urecholine and histamine in the stimulation of Heidenhain pouches. Gut, 5, 71-76.

Gregory, R. A. (1958). Gastric secretory responses after portal venous ligation. J. Physiol. (Lond.), 144, 123-127.

Johnson, L. R., and Grossman, M. I. (1969). Potentiation of gastric acid response in the dog. Gastroenterology, 56, 687-692. 
Konturek, S. J., and Oleksy, J. (1967). Potentiation between pentapeptide (ICI 50123) and histamine in the stimulation of gastric secretion in man. Gastroenterology, 53, 912-917.

Makhlouf, G. M., McManus, J. P. A., and Knill, J. R. (1968). Quantitative aspects of synergism and inhibition of gastric acid secretion. Gastroenterology, 54, 532-537.

Obrink, K. J. (1954). Bonedust-meat mixture as a test meal for continuous gastric secretion. Acta physiol. scand., 30, 275-281.

Passaro, E. P. Jr., Gillespie, I. E., and Grossman, M. I. (1963). Potentiation between gastrin and histamine in stimulation of gastric secretion. Proc. Soc. exp. Biol. (N.Y.), 114, 50-52.

Preshaw, R. M., and Webster, D. R. (1967). A comparison of sham feeding and teasing as stimuli for gastric acid secretion in the dog. Quart. J. exp. Physiol., 52, 37-43.

Rune, S. J. (1966). Comparison of the rates of gastric acid secretion in man after ingestion of food and after maximal stimulation with histamine. Gut, 7, 344-350.

Snedecor, J. W., and Cochran, W. G. (1968). Statisical Methods. Iowa State Press, Ames.

Thomas, J. E. (1941). An improved cannula for gastric and intestinal fistulas. Proc. Soc. exp. Biol. (N.Y.), 46, 260-261.

Thomas, W. R. G., and Forrest, A. P. M. (1967). Acid secretion from canine separated fundic pouches. Gastroenterology, 52, $192-197$. 